\title{
Therapeutic considerations or pharmacological treatment of delayed uterine clearance
}

\author{
Dale L. Paccamonti and Sara K. Lyle \\ Department of Veterinary Clinical Sciences, School of Veterinary Medicine, Louisiana State University, Baton Rouge
}

\begin{abstract}
Summary
Persistent mating induced endometritis and delayed uterine clearance have been shown to be significant causes of reproductive failure in mares. Various treatments have been suggested to remedy these problems, including pharmacological treatment with oxytocin and prostaglandin analogues. When choosing a particular drug to enhance uterine clearance, factors that may influence the success of treatment, as well as the likelihood of establishing pregnancy, should be considered. The time of treatment in relation to ovulation is one such factor. Oxytocin has a greater effect on uterine clearance before ovulation than afterwards. If oxytocin treatment is used after ovulation, the dose should be increased to achieve an effect. Although oxytocin has been shown to be very effective in enhancing uterine clearance, prostaglandin analogues have a longer duration of action and are preferred by some for that reason. Recent studies have shown that administration of prostaglandin or its analogues given shortly after ovulation can affect progesterone concentrations during early diestrus, potentially affecting the establishment of pregnancy. If sedation is used, drug choice can affect myometrial contractility. Xylazine increases uterine motility while acepromazine decreases it. Nonsteroidal anti-inflammatory drugs, such as phenylbutazone, decrease uterine clearance by interfering with endogenous prostaglandin. However, this effect can be overridden with exogenous oxytocin.
\end{abstract}

Keywords: mare, uterus, endometritis, clearance, oxytocin

\section{Aspekte der medikamentellen Behandlung der verzögerten Uterusclearance}

Persistierende nach der Belegung auftretende Endometritiden und verzögerte Uterusclearance wurden als signifikante Gründe für erfolglose Belegungen bei Stuten identifiziert. Verschiedenste Therapiekonzepte werden zur Behandlung dieser Probleme vorgeschlagen - einschließlich des medikamentellen Einsatzes von Oxyłocin und Prostaglandinanaloga. Bei der Wahl eines bestimmten Arzneimittels zur Förderung der uterinen Clearance müssen sowohl den Therapieerfolg beeinflussende Faktoren als auch eine mögliche Trächtigkeit Berücksichtigung finden. Oxyłocin hat präovulatorisch einen größeren Effekt auf die Uterusclearance als nach der Ovulation; daher sollte die Oxytocindosis bei postovulatorischem Einsatz erhöht werden. Obwohl sich Oxytocin als sehr effektiv in der Föderung der uterinen Clearance erwiesen hat, werden Prostaglandinanaloga aufgrund ihrer längeren Wirkungsdauer teilweise bevorzugt. Jüngste Studien zeigen, dass die Gabe von Prostaglandin oder seiner Analoga kurz nach der Ovulation die Progesteronkonzentration im frühen Diöstrus und damit die Etablierung einer Trächtigkeit beeinflussen kann. Einige Sedationsmittel zeigen Auswirkungen auf die Kontraktilität des Myometriums: Xylazin fördert die Uterusmotilität, während Acepromazin eine Abnahme dieser bewirkt. Nichtsteroidale Entzündungshemmer wie Phenylbutazon behindern durch Hemmung der endogenen Prostaglandinsynthese die uterine Clearance; diesem Effekt kann jedoch mittels Oxytocingabe entgegengewirkt werden.

Schlüsselwörter: Reproduktion, Stute, Uterus, Endometritis, Clearance, Oxytocin

Persistent mating induced endometritis associated with delayed uterine clearance has been shown to be a significant cause of reproductive failure in mares. Various treatments have been suggested to enhance uterine clearance and reduce the effects of persistent mating induced endometritis, including uterine ecbolics, uterine lavage, and intrauterine antibiotics. The success of such treatments can be influenced by a number of factors such as time of treatment in relation to ovulation, time of treatment in relation to mating, and other medications that may be administered concurrently.

Uterine activity is greater when the concentration of progesterone is low, such as before ovulation, than when progesterone concentrations are elevated (Cross and Ginther 1987). The inhibition of myometrial activity by elevated progesterone may necessitate modifications in treatment protocols in the post-ovulatory period. Myometrial activity measured by electromyography (emg) has been shown to be correlated to progesterone rather than estrogen (Taverne et al. 1979) and increases in intrauterine pressure after exogenous oxytocin are inversely related to the concentration of progesterone (Gutjahr et al. 2000). Moreover, reduced uterine cle- arance is observed under the influence of progesterone (Evans et al. 1986 and 1987). Therefore, it is preferable to treat mares with uterine clearance problems prior to ovulation rather than after. When comparing the effects of high and low dose oxytocin on intrauterine pressure, although both were effective pre-ovulation, only the high dose increased pressure post-ovulation (Gutjahr et al. 2000). Consequently, when using oxytocin after ovulation the dose should be adequate to enhance uterine clearance. Assuming good quality semen is used for breeding, it may be beneficial to breed a problem mare earlier, for example $48 \mathrm{~h}$ before ovulation rather than $24 \mathrm{~h}$, thus allowing a longer period for treatment to improve uterine clearance before progesterone begins to rise.

Oxytocin has been shown to be more effective than prostaglandin F2a (PGFa) or its analogues, at least in the short term, for enhancing uterine clearance (LeBlanc 1997). The action of oxytocin is rapid. After intrauterine infusion of radiocolloid during estrus, more than $90 \%$ of the colloid was cleared within 30 min (LeBlanc et al. 1994). When oxytocin was administered i.v., intrauterine pressure increased within two to three sec and gradually declined over the ensuing $30 \mathrm{~min}$ (Ko 
et al., 1989). The intensity of the uterine response to oxytocin dpends on the dose of oxytocin used, the route of administration and concentrations of steroid hormones in the mare at the time of treatment (Gutjahr et al. 2000, Madill et al. 2002, Sharpe et al. 1988). The duration of contractile activity after 20 or $40 \mathrm{U}$ of oxytocin is almost double that observed after 5 or $10 \mathrm{U}$ (Madill et al. 2002). Intravenous administration of oxytocin produced a more immediate increase in intrauterine pressure with a peak area under the curve almost twice that observed after intramuscular administration (Sharpe et al. 1988).

Because of the relatively short half-life of oxytocin (Paccamonti et al. 1999) drugs with a longer course of action have been sought. Comparing the effects of oxytocin with prostaglandin analogues, a response to oxytocin is seen almost immediately, with a peak of activity at 7 to $8 \mathrm{~min}$, returning to baseline within 10 to $20 \mathrm{~min}$. The increase in uterine activity after administration of prostaglandin analogues does not begin for 8 or $10 \mathrm{~min}$, with the peak of activity not occurring until 40 to 60 min after administration (Goddard and Allen 1985, Ley et al. 1988, Jones et al. 1991). Therefore, although uterine activity was greater after oxytocin during the first 10 min after administration, 45 min later uterine activity was greater for mares treated with prostaglandins (Ley et al. 1988). In most cases, it is not the rapidity or delay in the onset of action, but the duration of action that is of greatest concern for enhancing uterine clearance. A similar study reported the duration of effect with oxytocin and PGF2a as $1 \mathrm{~h}$ and 5 h, respectively (Troedsson et al. 1995). However, there was no difference in amplitude and intensity of myometrial activity between oxytocin and PGF2a during estrus (Troedsson et al. 1995).

One factor that should be considered when using prostaglandin analogues for treatment of delayed uterine clearance is the time of administration in relation to ovulation. Although it is widely accepted that the equine corpus luteum is resistant to the luteolytic effect of prostaglandin until five or six days post-ovulation, the resistance of the early corpus luteum to prostaglandin is not absolute. In early reports examining the timing of prostaglandin administration, two of five mares treated with $10 \mathrm{mg}$ PGF2a three days after ovulation responded by returning to estrus in two days after treatment (Oxender et al. 1975). Furthermore, recent work has shown repeated small doses of prostaglandin to be more effective than a single, even larger, dose in inducing luteolysis and a return to estrus (Irvine et al. 2002). An additional concern is evidence that luteal function may be affected, at least temporarily, by use of these drugs in the early post-ovulatory period. The eventual effect on the establishment of pregnancy is not clear but warrants consideration when prescribing treatment. Mares treated with cloprostenol or PGF2a on the day of ovulation ( $\mathrm{d}$ ) and the following $2 \mathrm{~d}$ had lower concentrations of progesterone during the first week of diestrus than mares treated with saline or oxytocin (Gunthle et al. 2000, Brendemuehl 2000). Mares treated twice daily with cloprostenol on d 0 similarly had lower progesterone concentrations than controls during the first week of diestrus (Brendemuehl 2000). Oxytocin, regardless of whether given once or twice a day, on d 0 and 1 , had no effect on progesterone, while cloprostenol treatment on $\mathrm{d} 0$ and 1 resulted in lower concentrations of progesterone on days 0 through 7, although concentrations of progesterone were similar to control mares for the remainder of diestrus (Brendemuehl 2001). The number of mares in each treatment group was small, affecting the power of statistical analyses, but pregnancy rates were $3 / 8$ for cloprostenol treated mares compared to $11 / 16$ for oxytocin and 5/8 for saline treated mares (Brendemuehl 2001). Then again, oxytocin administration every $6 \mathrm{~h}$ or cloprostenol every $24 \mathrm{~h}$, beginning $4 \mathrm{~h}$ post-insemination through $2 \mathrm{~d}$ post-insemination, resulted in lower concentrations of progesterone on days 2 through 7 and day 9 post ovulation in cloprostenol treated mares, but with no effect on pregnancy rates ( $\mathrm{Nie}$ et al. 2002). In another recent study, mares were treated with cloprostenol on d 0, 1 and 2, or only on d 2, after ovulation. Cloprostenol treatment, either on multiple days or a single day, affected progesterone production in early diestrus, but progesterone concentrations on day 14 were similar between treated and control mares. Pregnancy rates were $3 / 16$ for mares receiving cloprostenol on $\mathrm{d} 0,1$ and $2 ; 3 / 8$ for mares receiving cloprostenol on $\mathrm{d} 2$; and $5 / 8$ for control mares (Troedsson et al. 2001). Clearly, treatment with cloprostenol in the early post ovulatory period can affect progesterone production by the developing corpus luteum, however luteal function seems to be able to recover. When PGF2a, rather than cloprostenol, was used on days 0,1 and 2 , no effect was seen on progesterone concentrations through day 8 (Paccamonti et al. 1991). It may be that prostaglandin analogues, either because of increased potency or longer half-life, affect the developing corpus luteum more profoundly than PGF2a. Further work is needed to clarify the effect of prostaglandins or analogues administered in the early post-ovulatory period on the establishment of pregnancy. Nevertheless, reports to date indicate that the time of treatment in relation to ovulation, as well as the dose and number of treatments should be considered when using prostaglandin or analogues for improving uterine clearance. Although both oxytocin and prostaglandin analogues are effective and safe in the preovulatory period, after ovulation oxytocin requires a sufficient dosage to insure efficacy, while prostaglandin analogues should be used with caution.

Another factor to consider in the treatment of delayed uterine clearance is the concurrent use of other pharmaceuticals such as tranquilizers or nonsteroidal anti-inflammatory agents. The uterotonic effect seen after oxytocin administration is due to both a direct effect on the myometrium and also indirectly via a release of prostaglandin (Paccamonti et al. 1999). Nonsteroidal anti-inflammatory drugs, such as phenylbutazone, decrease uterine clearance by interfering with endogenous prostaglandin release. Phenylbutazone was found to inhibit uterine clearance, but when mares pre-treated with phenylbutazone were then treated with oxytocin, clearance of radiocolloid from the uterus was restored to that seen in control mares treated with only oxytocin (Cadario et al. 1995). Although inhibition of endogenous PGF2a through the use of nonsteroidal anti-inflammatory agents can potentially exacerbate a uterine clearance problem, the effect can be overridden with the appropriate use of exogenous oxytocin. Therefore, when anti-inflammatory drugs are used around the time of breeding, extra attention should be paid to uterine clearance and appropriate therapy instituted when needed.

The use of sedatives or tranquilizers may also affect uterine clearance. During diestrus, acepromazine suppressed uterine activity for $90 \mathrm{~min}$, while xylazine and detomidine increased uterine activity for 30 and $60 \mathrm{~min}$, respectively, and the manner in which uterine activity was affected was shown to differ between drugs (Gibbs and Troedsson 1995). Acepromazine 
decreased total uterine activity, duration and intensity of contractions but not the frequency (Gibbs and Troedsson 1995). Xylazine not only increased total activity, duration and intensity, but also increased the frequency of uterine contractions (Gibbs and Troedsson 1995, De Lille et al. 2000). Detomidine produced the greatest overall increase in total activity, increasing duration and intensity of uterine contractions but not affecting the frequency (Gibbs and Troedsson 1995). During estrus, normal mares sedated with detomidine had an increased number of contractions and increased maximum intrauterine pressure after oxytocin treatment compared to non-sedated mares (von Reitzenstein et al., 2002).

Some studies indicate that mares with delyed uterine clearance (DUC) have different patterns of uterine activity and respond to exogenous drugs in a different manner than normal mares. Normal mares have more contractions of longer duration and greater intensity than DUC mares (von Reitzenstein et al. 2002). Treatment with xylazine before oxytocin administration resulted in a longer duration of increased intrauterine pressure and a longer duration of the first contraction in DUC mares, but did not affect the number of contractions compared to normal mares (De Lille et al. 2000). Acepromazine pre-treatment resulted in a longer duration of the first contraction in DUC mares compared to normal mares, and to either control or xylazine treated DUC mares. Furthermore, after pre-treatment with acepromazine, the number of contractions in DUC mares after oxytocin was fewer than after pre-treatment with xylazine or saline (De Lille et al. 2000). Although detomidine augmented the uterotonic effect of oxytocin in normal mares, it did not have an effect in DUC mares (von Reitzenstein et al. 2002). When sedation is required, xylazine or detomidine are preferred over acepromazine because of their effect on uterine motility and clearance.

Knowledge of the various factors that can influence treatment of uterine clearance will aid in effective treatment and improve fertility. When choosing a particular drug to enhance uterine clearance, factors that may influence the success of treatment, as well as the likelihood of establishing pregnancy, should be considered.

\section{Literature}

Brendemuehl J. P. (2000): Influence of cloprostenol, PGF2a and oxytocin administered in the immediate post ovulatory period on corpora luteal formation and function in the mare. Proc. Ann. Conf. Soc. Therio., 267.

Brendemuehl J. P. (2001): Effect of oxytocin and PGF2a on luteal formation, function, and pregnancy rates in mares. Proc. Ann. Conven. Am. Assoc. Equine Prac., 239

Cadario M. E., Thatcher M.-J. D. and LeBlanc M. (1995): Relationship between prostaglandin and uterine clearance of radiocolloid in the mare. Biology of Reproduction Monograph 1, 495-500

Cross D. T. and Ginther O. J. (1987): The effect of estrogen, progesterone and prostaglandin $\mathrm{F} 2 \mathrm{a}$ on uterine contractions in seasonally anovulatory mares. Domest. Anim. Endocrinol. 4, 271-278

De Lille A. J. A. E., Silvers M. L., Cadario M. E., Tran T. Q., Cage C. L. and LeBlanc M. M. (2000): Interactions of xylazine and acepromazine with oxytocin and the effects of these interactions on intrauterine pressure in normal mares and mares with delayed uterine clearance. J. Reprod. Fertil. Suppl. $56,373-379$

Evans M. J., Hamer J. M., Gason L. M., Graham C. S., Asbury A. C. and Irvine C. H. G. (1986): Clearance of bacteria and non-antigenic markers following intra-uterine inoculation into maiden mares: Effect of steroid hormone environment. Theriogenology 26, 37-50

Evans M. J., Hamer J. M., Gason L. M. and Irvine C. H. G. (1987): Factors affecting uterine clearance of inoculated materials in mares. J. Reprod. Fertil. Suppl. 35, 327-334
Gibbs H. M. and Troedsson M. H. T. (1995): Effect of acepromazine, detomidine, and xylazine on myometrial activity in the mare. Biology of Reproduction Monograph 1, 489-493

Goddard P. J. and Allen W. E. (1985): Genital tract pressures in mares II. Changes induced by oxytocin and prostaglandin F2a. Theriogenology 24, 35-44

Gunthle L. M., McCue P. M., Farquhar V J. and Foglia R. A. (2000): Effect of prostaglandin administration postovulation on corpus luteum formation in the mare. Proc. Ann. Conf. Soc. Therio., 139

Gutjahr S., Paccamonti D. L., Pycock J. F., Taverne M. A. M., Dieleman S. J. and van der Weijden G. C. (2000): Effect of dose and day of treatment on uterine response to oxytocin in mares. Theriogenology 54, 447-456

Irvine C. H. G., McKeough V. L., Turner J. E., Alexander S. L. and Taylor T. B. (2002): Effectiveness of a two-dose regimen of prostaglandin administration in inducing luteolysis without adverse side effects in mares. Equine. Vet. J. 34, 191-194

Jones D. M., Fielden E. D. and Carr D. H. (1991): Some physiological and pharmacological factors affecting uterine motility as measured by electromyography in the mare. J. Reprod. Fertil. Suppl 44, 357-368

Ko J. C. H., Lock T. F., Davis J. L. and Smith R. P. (1989): Spontaneous and oxytocin-induced uterine motility in cyclic and postpartum mares. Theriogenology 32, 643-651

LeBlanc M., Neuwirth L., Mauragis D., Klapstein E. and Tran T. (1994): Oxytocin Enhances Clearance of Radiocolloid from the Uterine Lumen of Reproductively Normal Mares and Mares Susceptible to Endometritis. Equine. Vet. J. 26, 279-282

LeBlanc M. M. (1997): Effects of oxytocin, prostaglandin and phenylbutazone on uterine clearance of radiocolloid. Pferdeheilkunde 13, 483-485

Ley W.B., Purswell B. J. and Bowen J. M. (1988): The effects of prostalene and alfaprostol as uterine myotonics, and the effect on postpartum pregnancy rate in the mare following daily treatment with prostalene. Theriogenology 29, $1113-1121$

Madill S., Troedsson M. H. T., Santschi E. M. and Malone E. D. (2002): Doseresponse effect of intramuscular oxytocin treatment on myometrial contraction of reproductively normal mares during estrus. Theriogenology 58, 479-482

Nie G. J., Johnson K. E., Wenzel J. G. W. and Braden T. D. (2002): Effect of periovulatory ecbolics on luteal function and fertility. Theriogenology 58, 461-463

Oxender W. D., Noden P. A., Bolenbaugh D. L. and Hafs H. D. (1975): Control of estrus with prostaglandin F2a in mares: Minimal effective dose and stage of estrous cycle. Am. J. Vet. Res. 36, 1145-1147

Paccamonti D. L., Rodriguez H. F., Myers M. W., Eilts B. E. and Godke R. A. (1991): Effect of PGF2a or hCG administration during the early luteal phase on progesterone secretion in the mare. Proc. Ann. Conven. Am. Assoc. Equine Prac. 38, 151-159

Paccamonti D. L., Pycock J. F., Taverne M. A. M., Bevers M., van der Weijden G.C., Gutjahr S., Schams D. and Blouin D. (1999): PGFM response to exogenous oxytocin and determination of the half-life of oxytocin in nonpregnant mares. Equine. Vet. J. 31, 285-288

Sharpe K. L., Eiler H. and Hopkins F. M. (1988): Absence of uterokinetic effects of prostaglandin $\mathrm{F} 2 \mathrm{a}$ on oxytocin-reactive uterus in the mare. Theriogenology 30, 887-892

Taverne M. A. M., van der Weyden G. C., Fontijne P., Dieleman S. J., Pashen R. L. and Allen W. R. (1979): In-vivo myometrial electrical activity in the cyclic mare. J. Reprod. Fertil. 56, 521-532

Troedsson M. H. T., Liu I. K. M., Ing M. and Pascoe J. (1995): Smooth muscle electrical activity in the oviduct, and the effect of oxytocin, prostaglandin $\mathrm{F} 2 \mathrm{a}$, and prostaglandin E2 on the myometrium and the oviduct of the cycling mare. Biology of Reproduction Monograph 1 1, 475-488

Troedsson M. H. T., Ababneh M. M., Ohlgren A. F., Madill S., Vetscher N. and Gregas M. (2001): Effect of periovulatory prostaglandin F2 $\mathrm{a}$ on pregnancy rates and luteal function in the mare. Theriogenology 55, 1891-1899

von Reitzenstein M., Callahan M. A., Hansen P. J. and LeBlanc M. M. (2002): Aberrations in uterine contractile patterns in mares with delayed uterine clearance after administration of detomidine and oxytocin. Theriogenology $58,887-898$

Prof. Dale L. Paccamonti, DVM, MS, Dip ACT

Professor Theriogenology

Dept. Veterinary Clinical Science

School Veterinary Medicine

Lovisiana State University

Baton Rouge, Louisiana 70803, USA

pacc@lsu.edu 